\title{
Phenolic Compounds from The Stem Bark Erythrina Orientalis and Detection of Antimalaria Activity by ELISA
}

\author{
Tjitjik Srie Tjahjadarie*, Ratih Dewi Saputri, and Mulyadi Tanjung \\ Natural Products Chemistry Research Group, Organic Chemistry Division, Department of Chemistry, \\ Faculty of Science and Technology, Universitas Airlangga \\ *Corresponding author email: tjitjiktjahjandarie@gmail.com
}

\begin{abstract}
Erythrina orientalis has local name "Dadap". This plant has known producing alkaloids, flavonoids, pterocarpans, stilbenes, and arylbenzofurans which are active compounds.Three prenylated flavonoids, 8prenyl-daidzein (1), alpinumisoflavone (2) and 4'-O-methyl licoflavanone (3) had been isolated from the stem bark of Erythrina Orientalis. The structures were elucidated on the basis of spectroscopic data, which are IR, UV, MS, and NMR 1D ( ${ }^{1} \mathrm{H}-\mathrm{NMR}$ and $\left.{ }^{13} \mathrm{C}-\mathrm{NMR}\right)$ and 2D (COSY, HMQC, and HMBC).
\end{abstract}
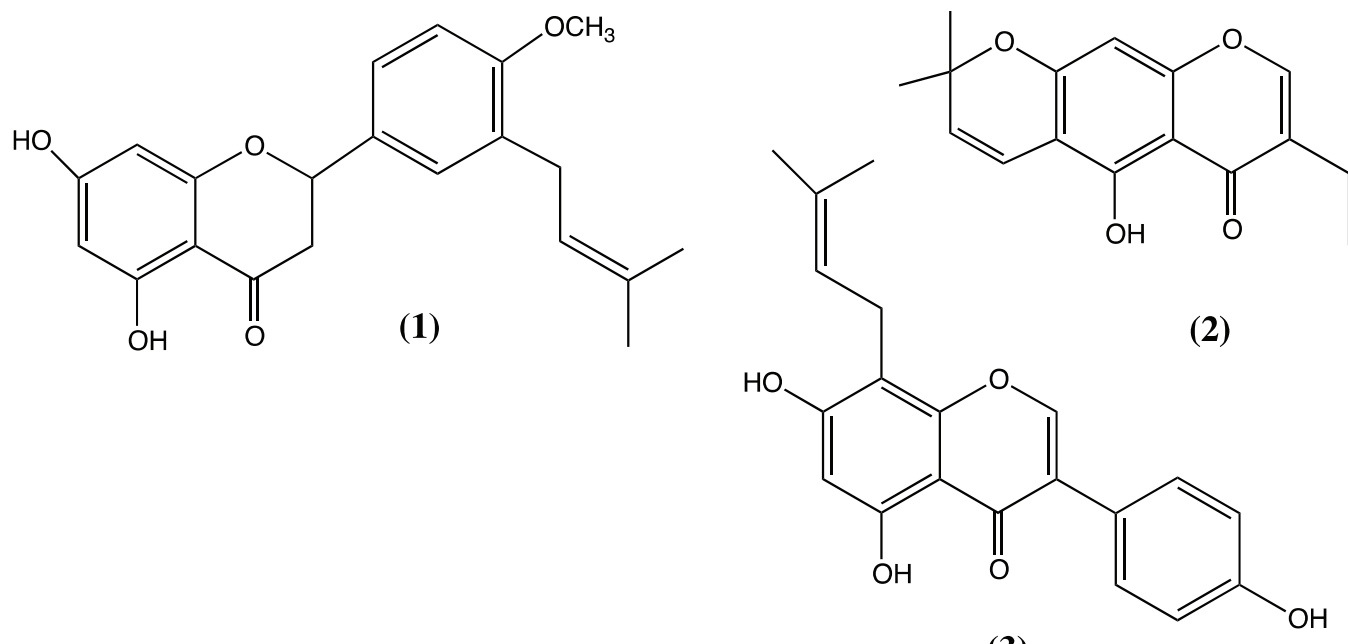

(3)

Compounds 1-3 were evaluated for their antimalaria with ELISA methods, which showed percentage inhibition values of $74.46 \%, 62.06 \%$, and $0 \%$ respectively. Based on the inhibition value showed 4'-O-methyl licoflavanone (1) exhibit very high antimalaria activity compared to compounds (2) and (3).

Keywords: Pterocarpan, Flavonoid, Erythrina Orientalis, Antimalaria

\section{Introduction}

Malaria remains world's one of the most devastating human parasitic infection affecting more than 500 million people and causing about 1-3 million deaths each year. This disease has been found as endemic in all region of Indonesia. Recently, chloroquine and artemisinin have used as antimalaria drug and showed resistance against Plasmodium parasites in Indonesia[1]. Erythrina is a large genus of Leguminosae family consisting of about 120 species and distributed in the tropical and subtropical region, including Indonesia [1]. The phytochemical studies of Erythrina have been known that these plants producing alkaloids [2,3], flavonoids [4,5], pterocarpans [6,7], stilbenes [8], and 